\title{
A Modern Approach to the Heckel Equation: The Effect of Compaction Pressure on the Yield Pressure of Ibuprofen and its Sodium Salt
}

\author{
Hooper $\mathrm{D}^{1,2 *}$, Clarke FC ${ }^{2}$, Mitchell $\mathrm{JC}^{1 *}$ and Snowden $\mathbf{M} \mathbf{J}^{1}$ \\ ${ }^{1}$ Faculty of Engineering and Science, University of Greenwich, Medway, ME4 4TB, UK \\ ${ }^{2}$ Pfizer Sandwich, Ramsgate Road, CT13 9ND, UK
}

\begin{abstract}
Despite being heavily criticised in the literature the most widely used and accepted compaction equation is the Heckel equation proposed by Heckel in 1961. Its presence in literature for 55 years is due to the ease in which it can distinguish between plastic and brittle materials. Achieving the correct balance of plastic and brittle materials in a formulation is critical to ensure adequate tablet strength is achieved therefore classifying materials using the Heckel equation is attractive. Despite the importance of this understanding, especially in the design and manufacture of direct compression formulations, there are no set analytical testing standards or materials classification guidelines. Instead many workers have attempted to develop techniques for the measurement and classification of a materials deformation but there is still confusion and contradiction present in this field.
\end{abstract}

In this study we report the effect of compaction pressure on the yield pressure of ibuprofen and its sodium salt. Ibuprofen and its sodium salt were selected as models for study due to the availability of comparative literature yield pressure values. The reported variation in yield pressure can be significant e.g, ibuprofen which has literature values of 21-1139 MPa. This study proposes an approach to determine yield pressure from the Heckel equation using a linear regression method. The full linear regression methodology utilised is described and is used to report the yield pressure of ibuprofen and its sodium salt dihydrate. This technique reveals the most representative compaction pressure in order to derive yield pressure to be $121 \mathrm{MPa}$.

The yield pressure of ibuprofen and its sodium salt have been shown to increase with increasing compaction pressure. The reported values lie between 52-78 MPa for ibuprofen and 48-75 MPa for ibuprofen sodium dihydrate. The slightly lower reported yield pressure values for ibuprofen sodium suggest increased plasticity which could be attributed to the water contained within the structure acting as a plasticiser.

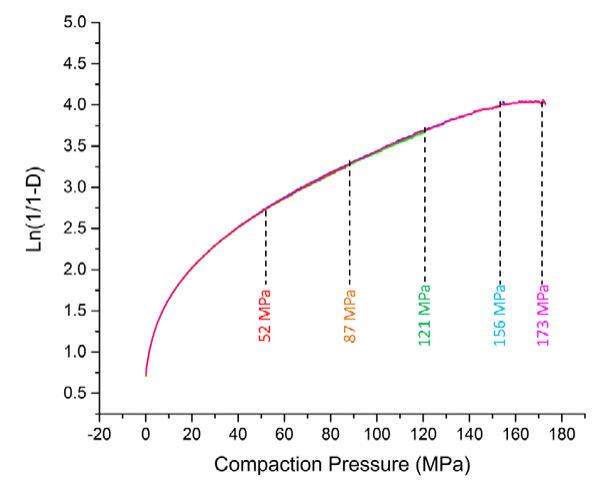

Ibuprofen Heckel transformation at varying compaction pressures.

Keywords: Heckel equation; Deformation; Yield pressure; Linear regression; True density

\section{Introduction}

As tablets are the most common dosage platform understanding the deformation behaviour of the individual components is critical. Despite the importance of this understanding, especially in the design and manufacture of direct compression formulations, there are no set analytical testing standards or materials classification guidelines. Instead many workers have attempted to develop techniques for the measurement and classification of a materials deformation but there is still confusion and contradiction present in this field.

Recently many efforts have focused on the study of a materials deformation at single crystal level [1-4]. Techniques such as nanoindentation provide information using minimal quantities of material however the relationship between single crystal and bulk mechanical behaviour is not well understood. This had led to the continued use of compaction equations to classify materials in terms of their deformation.

*Corresponding authors: Hooper D, Pfizer Sandwich, Ramsgate Road, CT13 9ND, UK, E-mail: Debbie.Hooper@pfizer.com

John Mitchell, Medway Centre for Formulation Sciences, Faculty of Science and Engineering, The University of Greenwich at Medway, Central Avenue, Chatham Maritime, ME4 4TB, UK, E-mail: j.mitchell@gre.ac.uk

Received June 09, 2016; Accepted June 14, 2016; Published June 21, 2016

Citation: Hooper D, Clarke FC, Mitchell JC, Snowden MJ (2016) A Modern Approach to the Heckel Equation: The Effect of Compaction Pressure on the Yield Pressure of Ibuprofen and its Sodium Salt. J Nanomed Nanotechnol 7: 381. doi:10.4172/2157-7439.1000381

Copyright: $\odot 2016$ Hooper D, et al. This is an open-access article distributed under the terms of the Creative Commons Attribution License, which permits unrestricted use, distribution, and reproduction in any medium, provided the original author and source are credited. 
Despite being heavily criticised in the literature the most widely used and accepted compaction equation is the Heckel equation proposed by Heckel in 1961. Its presence in literature for 55 years is due to the ease in which it can distinguish between plastic and brittle materials. Achieving the correct balance of plastic and brittle materials in a formulation is critical to ensure adequate tablet strength is achieved therefore classifying materials using the Heckel equation is attractive.

The model proposed by Heckel [5] is represented by the following equation:

$$
\ln (1 / 1-\mathrm{D})=\mathrm{K} \cdot \mathrm{P}+\mathrm{A}
$$

where $\mathrm{D}$ is the relative density of the compact, $\mathrm{P}$ is the applied pressure, $A$ is a constant suggested to represent particle rearrangement and the reciprocal of $\mathrm{K}$ is used to calculate apparent mean yield pressure $\left(\mathrm{P}_{\mathrm{y}}\right)$. The density pressure relationship is based on first order kinetics and has been defined as the stress at which plastic deformation of a particle is initiated, where low $\mathrm{P}_{\mathrm{y}}$ values represent plastically deforming materials and high $\mathrm{P}_{\mathrm{y}}$ values represent brittle materials [6]. In the pharmaceutical industry, the deformation of excipients has been most widely characterised [7] and it is accepted that microcrystalline cellulose (MCC) and dibasic calcium phosphate (DCP) form the extremes of the deformation spectrum with MCC (Avicel PH-101) exhibiting a yield pressure of $50 \mathrm{MPa}$ and DCP exhibiting a yield pressure value of $957 \mathrm{MPa}$ [8].

The yield stress values of well characterised materials become important when attempting to classify new materials. Often a comparison to materials whose deformation behaviour is well understood will be made due to the absence of defined standard class limits on yield pressure in terms of a plastic or brittle material. Roberts and Rowe attempted to set limits on these values along with other mechanical descriptors including young's modulus, hardness and strain rate sensitivity which allowed materials to be categorised [8]. Materials with $\mathrm{P}_{\mathrm{y}}<80$ were classified as soft/plastic materials whereas $\mathrm{P}_{\mathrm{y}}>80$ indicated ${ }^{\mathrm{y}}$ hard/brittle substances. Although these limits are available they are difficult to adhere to due to variation present in $\mathrm{P}_{\mathrm{y}}$ values for the same material between research groups. The variation present is due to many experimental and physical factors (experiment type, compaction speed, compaction pressure and particle size) affecting derived values and no standardisation being set on these.

The Heckel equation can be fitted to data collected from 'in-die' or 'out-of-die' compaction experiments. These different experiment types have been shown to affect yield pressure measurements due to the contribution of elastic energy $[9,10]$. Ilić et al., measured the yield pressure of MCC (Avicel PH 101) in-die and out-of-die and the respective yield pressure values were $61.7 \mathrm{MPa}$ and $98.3 \mathrm{MPa}$. This difference of $36.6 \mathrm{MPa}$ between experiment types is one of many factors contributing to discrepancies in yield pressure data published from different research groups.

As well as experiment type, it is also well documented that experimental conditions can affect yield pressure. It has been shown by numerous workers that compaction speed and final compaction pressure can affect yield pressure [11-13]. Roberts and Rowe proposed a term, strain rate sensitivity [14], which describes the relationship between yield pressure values collected at two different compaction speeds. Since then it has been shown that plastic materials are more sensitive to strain rate compared to brittle materials [15]. This means that when reporting the yield pressure of plastic materials, the compaction speed will alter the yield pressure value.

The variation seen in yield pressure is not only due to experimental conditions but can be attributed to the physical effect of particle size. A materials yield pressure is an intrinsic property and therefore should not be affected by physical properties such as particle size however there is contradicting information in the literature. Fell and Newton [16] described early on that the yield pressure of lactose was influenced by particle size. However, in 1982 a study by McKenna and McCafferty [17] revealed that during their calculation of yield pressure, particle size was irrelevant for lactose. Another study by Patel et al. [18] found that the yield pressure of paracetamol was dependant on particle size, where increasing particle size resulted in higher yield pressure values. Recent studies have suggested that as the yield pressure is derived from the density pressure relationship this value is actually an indication of powder densification rate that may be effected by particle size [19]. Nevertheless, yield pressure calculated from the Heckel equation is still derived to provide information on bulk deformation behaviour and particle size is one of the many variables affecting the outcome.

One area which may account for variability in the yield pressure value, but has been neglected in the literature, is the way in which $\mathrm{K}$ from the Heckel equation is derived. This is due to the fact that although it is accepted that yield pressure is derived from the gradient of a linear slope, Heckel plots are not completely linear and contain deviations at low and high pressures. These deviations are due to particle rearrangements at low pressures [6], and elastic deformation as pressure increases [9]. It is the responsibility of the analyst to select the most appropriate region in which to calculate yield pressure. This method is susceptible to user subjectiveness and has the potential to cause error in derived values which could lead to mistakes in material classification. Despite this, there are no standards or recommendations in the literature to define what area should be used in order to calculate yield pressure.

The type of variation in yield pressure that can be seen for a material, due to the factors discussed, can be significant e.g, ibuprofen which has reported values of 21-1139 $\mathrm{MPa}$. The compressibility of ibuprofen has been studied by many workers [20-23] and a table listing the reported yield pressure values is shown in Table 1 . The small variations present in studies, $4 \mathrm{MPa}$ for Di Martino et al. [21] and $3 \mathrm{MPa}$ for Liu et al [23], are due to particle habit and particle size differences, respectively. The study by Patel et al. [22] reveals large differences accounted for by the effect of compaction pressure. This would suggest, according to the limits set by Rowe and Roberts, [8], that ibuprofen is changing from a plastic to brittle material. In an attempt to further understand these variations within the literature this study will focus on the effect of compaction pressure on ibuprofen yield pressure and the method to determine the linear region.

\section{Materials and Methods}

\section{Materials}

Ibuprofen $(40 \mu \mathrm{m}$ grade) was supplied by Pfizer Ltd. Ibuprofen sodium dihydrate was purchased from Sigma Aldrich, Dorest, UK.

\section{Methods}

Scanning electron microscopy: Scanning Electron Microscopy (SEM) was used to qualitatively assess particle size and shape. Electron micrographs were captured using a Zeiss SUPRA 40VP (Carl Zeiss Microscopy GmbH, Cambridge, UK). The samples were mounted onto an aluminium pin stub containing sticky carbon tabs and sputter

\begin{tabular}{|c|c|c|}
\hline Py (MPa) & Lead Author & Comment \\
\hline $54-58$ & Di Martino et al. [21] & Particle habit dependant \\
\hline $21-24$ & Liu et al. [23] & Particle size dependant \\
\hline $98-1139$ & Patel et al., [22] & Compaction pressure dependant \\
\hline \multicolumn{2}{|r|}{ Table 1: Reported yield pressure values from literature. } \\
\hline
\end{tabular}


Citation: Hooper D, Clarke FC, Mitchell JC, Snowden MJ (2016) A Modern Approach to the Heckel Equation: The Effect of Compaction Pressure on the Yield Pressure of Ibuprofen and its Sodium Salt. J Nanomed Nanotechnol 7: 381. doi:10.4172/2157-7439.1000381

coated with platinum. A voltage of $3.0 \mathrm{kV}$ and working distance of 10 mm were used.

Laser diffraction: Laser diffraction was utilised to measure the particle size of the ibuprofen samples. Dry dispersion measurements using $200 \mathrm{mg}( \pm 5 \mathrm{mg})$ of sample were made at a pressure of $1 \mathrm{bar}$ using a Sympatec HELOS laser diffraction system with an R5 lens in conjunction with a RodosM disperser and an Aspiros feeder controlled by WINDOX software (Sympatec GmbH, Germany). Samples were measured in triplicate.

True density: The true density of $2.5 \mathrm{~g}( \pm 0.2 \mathrm{~g})$ samples were measured in duplicate using a Pentapyc 5200e helium pycnometer (Quantachrome UK Ltd., Hook, UK).

Compression studies: A Gamlen GTP-1 single punch bench top tablet press which has a uni-axial saw tooth displacement profile (Gamlen Tableting, United Kingdom) was used to complete the compression experiments. The deformation of the punches was corrected by compacting an un-deformable metal disk.

Tablets of $100 \mathrm{mg}( \pm 5 \mathrm{mg})$ were produced using a $6 \mathrm{~mm}$ flat-faced punch and die. Compression events were made at a speed of $0.033 \mathrm{~mm}$ second $^{-1}$, following the same methodology described by Roberts and Rowe [11].

In order to investigate the effect of compression pressure on yield pressure ibuprofen and ibuprofen sodium were compacted to five different compaction pressures $(52,87,121,156$ and $173 \mathrm{MPa})$. Six individual measurements were made at each compaction pressure for both materials, to enable the variation in the yield pressure for each material to be determined.

\section{Results and Discussion}

\section{Scanning electron microscopy}

Scanning electron microscopy was conducted to visually assess and qualitatively determine particle size and shape information. The electron micrographs of ibuprofen and ibuprofen sodium, shown in Figure $1 \mathrm{a}$ and $1 \mathrm{~b}$ respectively, reveal a difference in size and shape between the two materials. The majority of ibuprofen particles are smaller than $100 \mu \mathrm{m}$ and have a size of around $40 \mu \mathrm{m}$ whereas the ibuprofen sodium batch contains both small (around $40 \mu \mathrm{m}$ ) and larger particles (around $200 \mu \mathrm{m}$ ). Differences in particle shape are also revealed, with ibuprofen consisting of smooth lath shaped particles compared to ibuprofen sodium which has both rough prismatic and lath shaped particles.

\section{Particle size distribution}

Ibuprofen and ibuprofen sodium were characterised using laser diffraction to enable a quantitative measure of particle size. The volume based particle size distribution for both materials are shown in Figure 2. The distributions reveal that ibuprofen contains a primary mode centring around $40 \mu \mathrm{m}$, which is in agreement with the visual observation. The distribution for ibuprofen sodium reveals that the main mode centres around $200 \mu \mathrm{m}$ and has a wider distribution compared to ibuprofen. The cumulative underscore values are presented in Table 2 and shows that $50 \%$ of particles are $<39.3 \pm 0.2 \mu \mathrm{m}$ for ibuprofen whereas this value is almost doubled at $71.7 \pm 2.4 \mu \mathrm{m}$ for ibuprofen sodium.

\section{True density}

Helium pycnometry was used to measure the true density of the materials. The true density values of ibuprofen and ibuprofen sodium

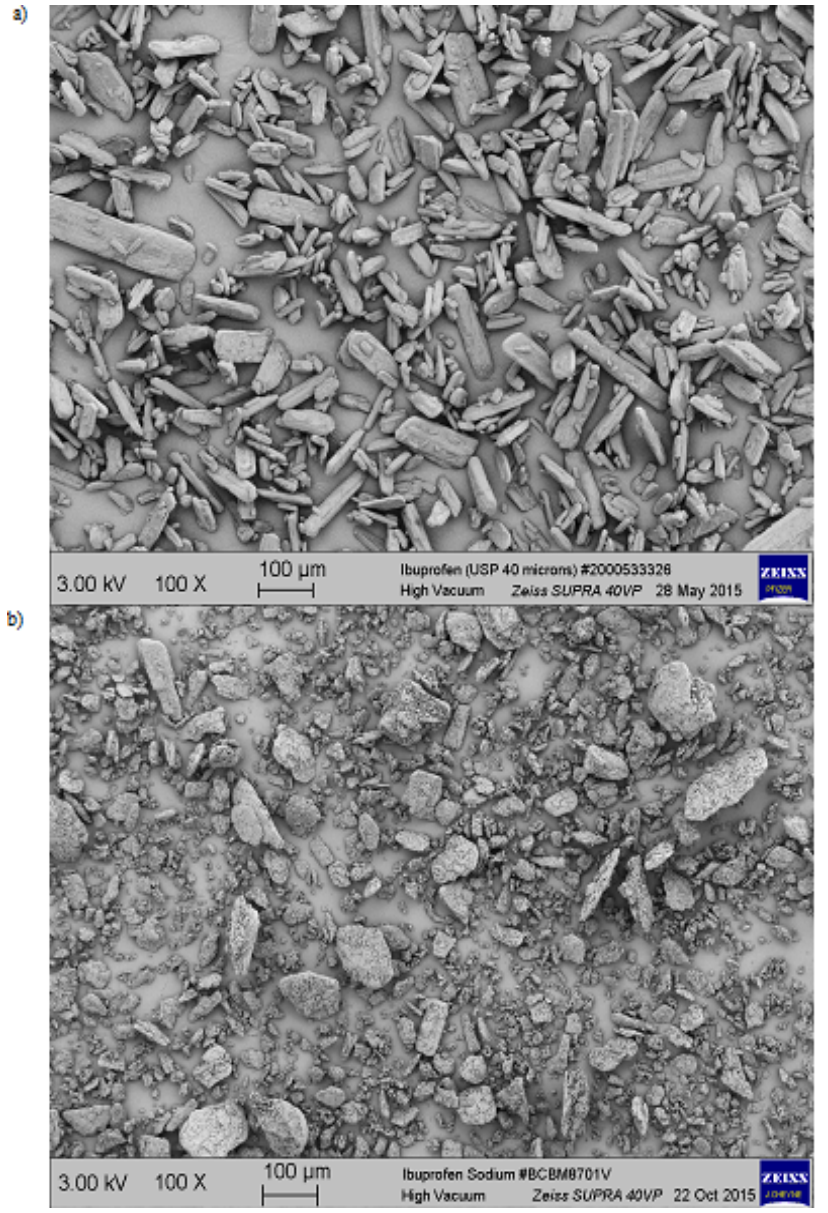

Figure 1: Electronmicrograph showing a) ibuprofen $(x 100)$ and b) ibuprofen sodium (x100).

\begin{tabular}{|c|c|c|c|}
\hline Material & $\mathrm{d} 10(\mu \mathrm{m})$ & $\mathrm{d} 50(\mu \mathrm{m})$ & $\mathrm{d} 90(\mu \mathrm{m})$ \\
\hline Ibuprofen & $13.5(0.2)$ & $39.3(0.2)$ & $86.4(0.4)$ \\
\hline Ibuprofen sodium & $6.2(0.4)$ & $71.7(2.4)$ & $253.6(4.6)$ \\
\hline
\end{tabular}

Table 2: Particle size values calculated by laser diffraction for ibuprofen and ibuprofen sodium where standard deviations of 3 runs are shown in brackets.

were $1.12 \mathrm{~g} / \mathrm{cm}^{3}$ and $1.17 \mathrm{~g} / \mathrm{cm}^{3}$, respectively. The standard error of measurement for each material was calculated and determined to be $0.0013 \mathrm{~g} / \mathrm{cm}^{3}(0.11 \%)$ for ibuprofen and $0.007 \mathrm{~g} / \mathrm{cm}^{3}(0.61 \%)$ for ibuprofen sodium.

It has previously been reported that Heckel plots are sensitive to variations in measured density, $1 \%$ error in density can lead to $10 \%$ error in yield pressure estimate [19], therefore it is important to report density values used and include the standard error in the measurement for transparency. Since the error values are low it is predicted that this will have minimal effect on derived values however the impact or error in density will be investigated during yield pressure calculations.

\section{Yield pressure determination}

In Die Heckel calculation: In-die Heckel plots were obtained by calculating the relative density (D) in-die using the true density and compact thickness (derived from corrected punch displacement). The $\ln (1 / 1-D)$ was determined for each measurement at each compaction pressure and these were plotted against each other to enable yield pressure to be determined. 
Citation: Hooper D, Clarke FC, Mitchell JC, Snowden MJ (2016) A Modern Approach to the Heckel Equation: The Effect of Compaction Pressure on the Yield Pressure of Ibuprofen and its Sodium Salt. J Nanomed Nanotechnol 7: 381. doi:10.4172/2157-7439.1000381

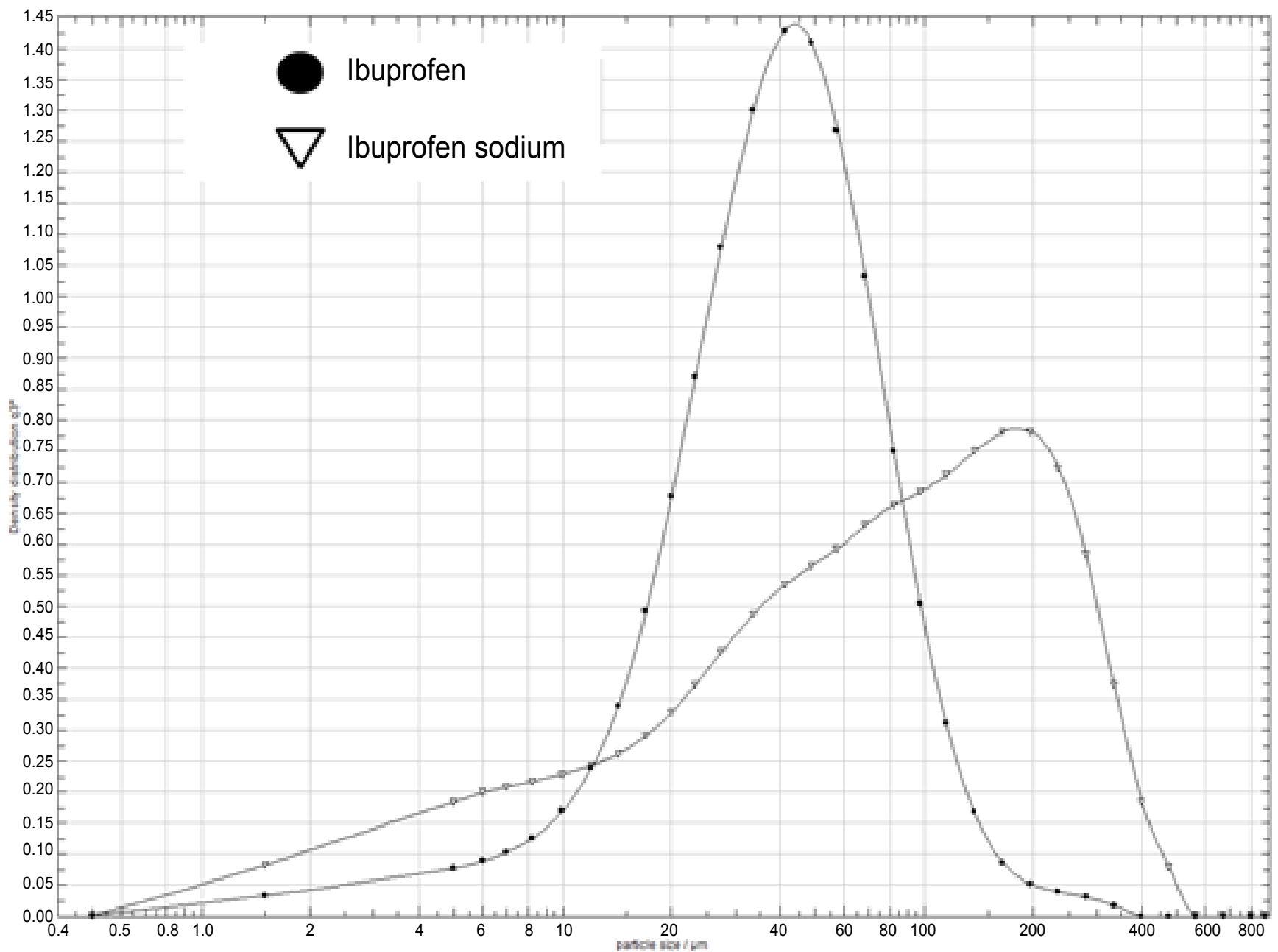

Figure 2: Laser diffraction particle size distribution for ibuprofen and ibuprofen sodium.

Linear regression fitting: To enable accurate determination and eliminate subjective selection of the linear region of the plot, linear regression analysis was performed. A qualitative assessment to select the most central part of the linear region was made. The regression coefficient for this selected region was calculated. The linear region was then extended in both directions and on each occasion the regression coefficient recalculated. This was achieved by extending the linear range, one $\mathrm{x}$ coordinate at a time, in approximately $10 \mathrm{MPa}$ steps. Once the region which contained the highest regression coefficient (specific to $\mathrm{x}$ coordinate) was established the step size was decreased until an accuracy of $1 \mathrm{MPa}$ was reached.

The effect of the regression coefficient on the gradient of the slope and hence the yield pressure is highlighted using an example of ibuprofen compacted to $121 \mathrm{MPa}$ (repeat 1) in Figure 3. This reveals the importance of selecting the most representative linear region as selecting only a small portion of the plot, where $\mathrm{r}^{2}$ is 0.984 , gives rise to a yield pressure value of $85 \mathrm{MPa}$ compared to a larger portion of the plot $\left(\mathrm{r}^{2}\right.$ is 0.999$)$ which gives rise to a yield pressure value of 76 $\mathrm{MPa}$, a difference of around 10\%. According to Rowe and Roberts, [8] this would classify ibuprofen in two different categories, changing from hard/brittle to soft/plastic.
Effect of compaction pressure on derived yield pressure: Heckel transformations for ibuprofen at the different compaction pressures analysed are shown in Figure 4. The plots produced at each compaction pressure overlay suggesting that in principal the same linear region for each pressure could be selected and therefore deriving the same yield pressure results. However, the plot also reveals that the full linear range of the Heckel plot may only become apparent when higher final pressures are used.

Linear regression was performed on six Heckel plots at each compaction pressure for ibuprofen and ibuprofen sodium. During analysis it became apparent that differences in yield pressures arise due to the range of the linear region available for selection at different compaction pressures. Figure 5 shows an example where ibuprofen compacted to $52 \mathrm{MPa}$ returns a yield pressure value of 48 $\mathrm{MPa}$ compared to $76 \mathrm{MPa}$ for ibuprofen compacted to $121 \mathrm{MPa}$. The visually subtle difference in gradient due to the compaction pressure used causes a significantly large difference in yield pressure, $28 \mathrm{Mpa}$. Compacting ibuprofen to higher compaction pressures extends the rate of powder densification which in turn lowers the gradient of the slope and explains the increase in yield pressure values. 


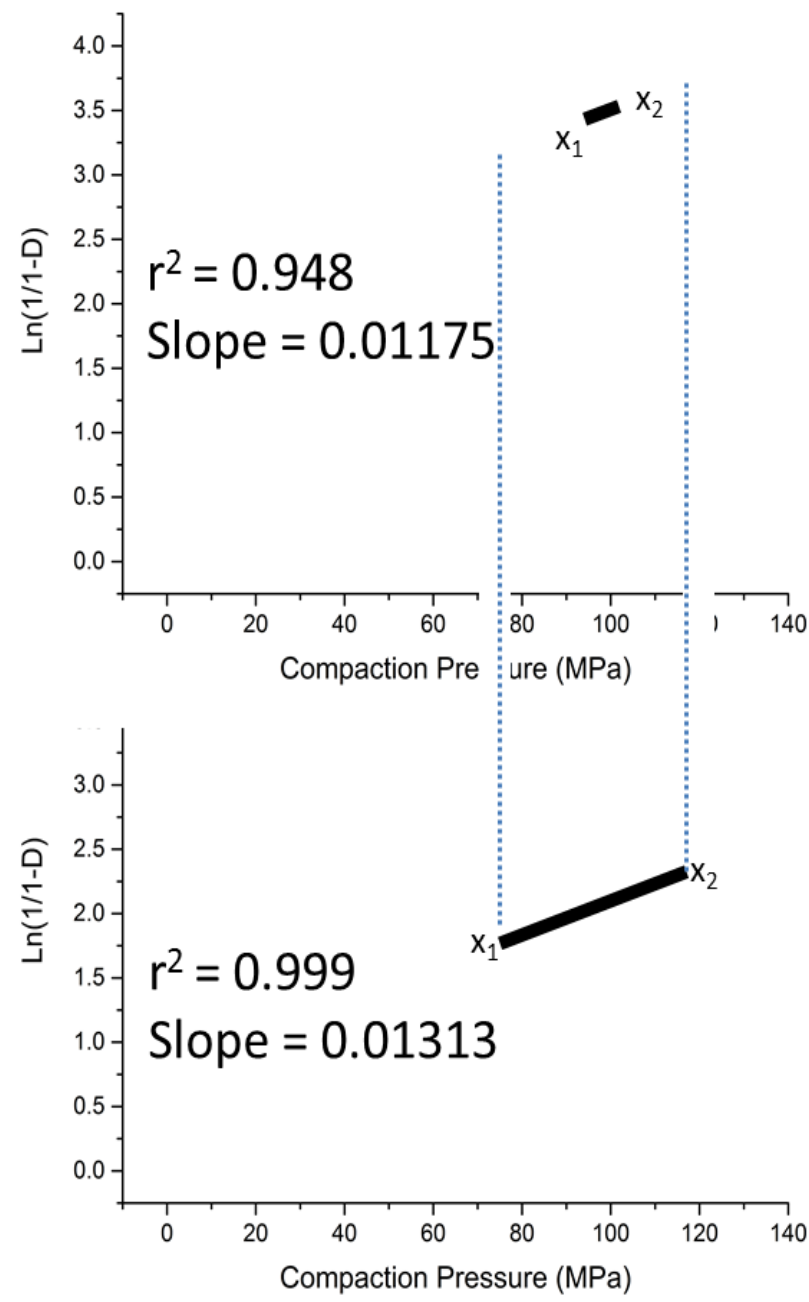

Figure 3: An example of the extension of the linear range of the Heckel model in order to achieve the highest regression coefficient.

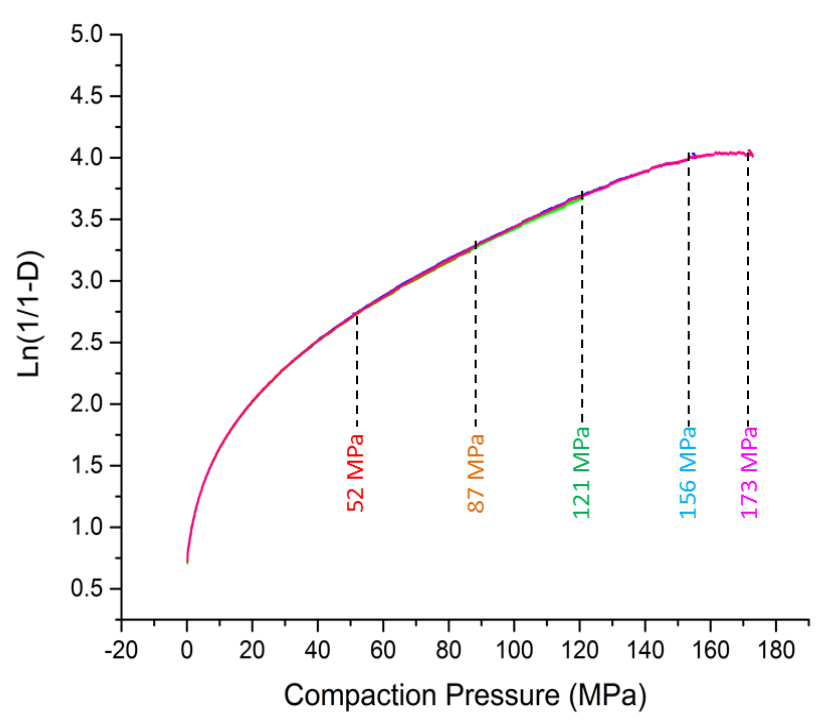

Figure 4: Heckel transformations of ibuprofen at varying compaction pressures.
Investigating the effect of error in true density: As discussed previously, it is known that error in measured true density can affect derived yield pressure values. To investigate this further a worst case scenario of ibuprofen sodium compacted to $52 \mathrm{MPa}$ was chosen for investigation, due to ibuprofen sodium containing $0.5 \%$ higher error in density compared to ibuprofen. This measurement gave a yield pressure of $50 \mathrm{MPa}$ and when the error in density was included returned values of 46 and $53 \mathrm{MPa}$ which is a difference of around $14 \%$. This large error associated with density is unavoidable due to the logarithmic transformation of the Heckel equation; therefore alternative methods to reduce error are of upmost importance.

Comparison of Ibuprofen and Ibuprofen Sodium: The effect of compaction pressure on yield pressure for ibuprofen and ibuprofen sodium is displayed in Figure 6. The derived value for ibuprofen ranges from 52-78 $\mathrm{MPa}$ and ranges from 48-75 $\mathrm{MPa}$ for ibuprofen sodium. At the very high compaction pressures $(>156 \mathrm{MPa})$ it is observed that the yield pressure values for both materials reaches a plateau where the standard deviations overlap. This would suggest that at these compaction pressures the highest possible rate of powder densification has been reached however examination of Figure 3 reveals that in order to utilise the greatest range of linearity, final compaction pressures of $121 \mathrm{MPa}$ should be used to report yield pressure values.

The comparison of ibuprofen yield stress to its sodium salt dihydrate reveals that at all compaction pressures ibuprofen sodium exhibits lower yield stress values. It would be expected from the results of previous studies that ibuprofen sodium would exhibit a smaller particle size distribution which would account for the difference [18]. However, examination of the particle size data (Figure 2) reveals that the salt contains a larger particle size. Therefore regardless of particle size, ibuprofen sodium dihydrate possesses an increased powder densification rate suggesting higher plasticity compared to the free acid. The water contained within the crystal structure of the sodium salt could be acting as a plasticiser allowing the easier slip to take place. This could explain the lower yield stress and therefore plasticity of ibuprofen sodium dihydrate compared to ibuprofen free base.

\section{Conclusion}

A new approach utilising linear regression has been developed to analyse Heckel plots. Examination of regression coefficients of the linear region of the plot has allowed the selection of the most representative area in which yield stress can be derived. The variation due to the linear region selection has been reviewed and revealed that variations of $10 \%$ are possible dependant on which part of the plot is selected.

This linear regression method has been effectively applied to ibuprofen and ibuprofen sodium dihydrate and highlights that increasing compaction pressure results in the calculation of higher yield pressure values. This phenomena reaches its peak at very high compaction pressures $(>156 \mathrm{MPa})$ however the greatest range of linearity is observed when pressures of $121 \mathrm{MPa}$ were used in this study. Therefore it is proposed to enable valuable comparison of yield pressure, high compaction pressures (around $121 \mathrm{MPa}$ ) should be used for analysis. We hope to extend this strategy to other pharmaceutical materials.

It is also proposed from this research that when reporting yield pressure values from the Heckel equation that all experimental conditions and linear regression methods should be clear and transparent in order to reliably classify materials. 
Citation: Hooper D, Clarke FC, Mitchell JC, Snowden MJ (2016) A Modern Approach to the Heckel Equation: The Effect of Compaction Pressure on the Yield Pressure of Ibuprofen and its Sodium Salt. J Nanomed Nanotechnol 7: 381. doi:10.4172/2157-7439.1000381

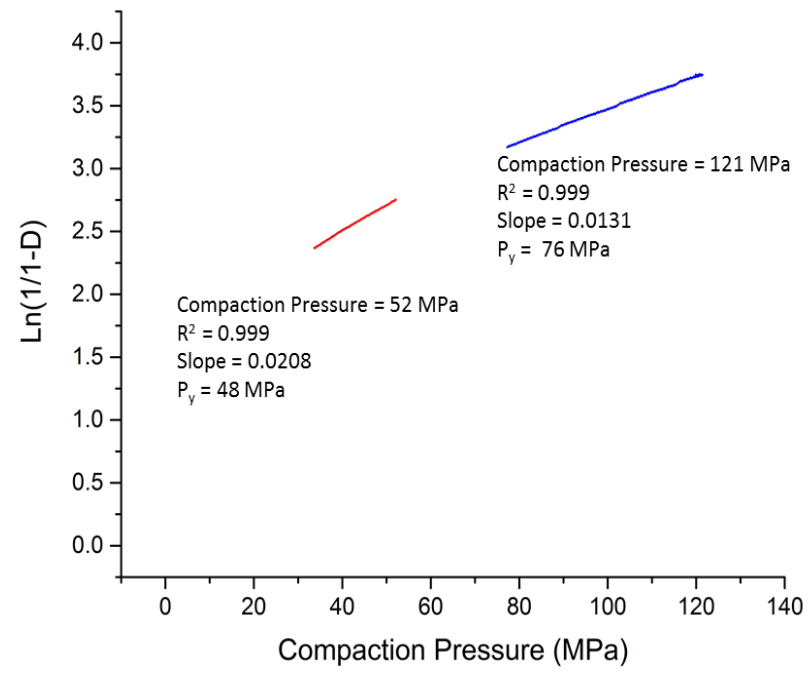

Figure 5: Derived yield pressure from Heckel plot at $52 \mathrm{MPa}$ and $121 \mathrm{MPa}$

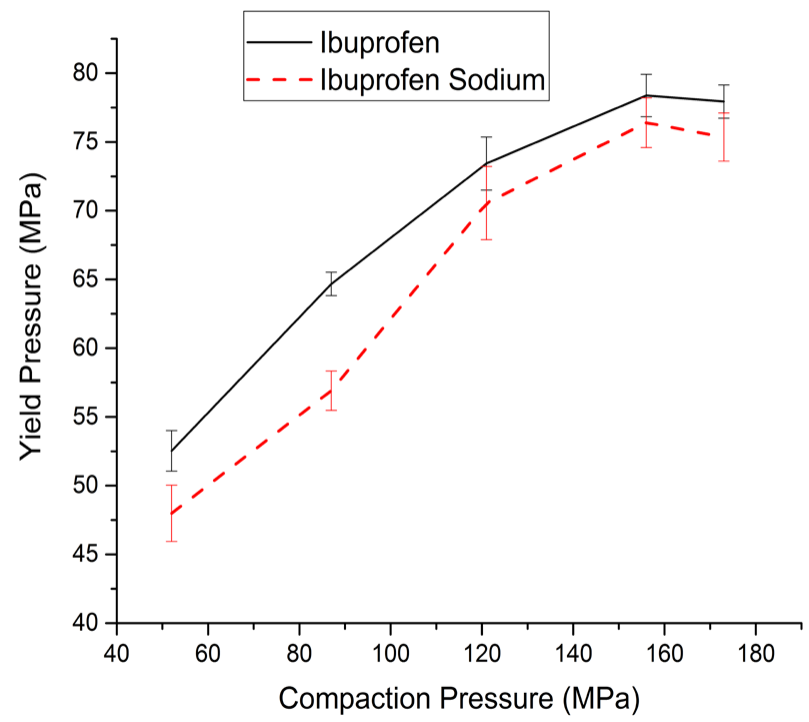

Figure 6: Effect of compaction pressure on yield for ibuprofen and ibuprofen sodium.

\section{Acknowledgments}

Pfizer Ltd are greatly acknowledged for the funding of this study. Callum Cameron and Jordan Cheyne are acknowledged for SEM and laser diffraction data collection.

\section{References}

1. Taylor LJ, Papadopoulos DG, Dunn PJ, Bentham AC, Mitchell PJ, et al. (2004) Mechanical characterisation of powders using nanoindentation. Powder Technology 179-185.

2. Meier, John E, Wieckhusen D, Wirth W, Peukert W (2009) Influence of mechanical properties on impact fracture: Prediction of the milling behaviour of pharmaceutical powders by nanoindentation. Powder Technology 188: 301-313.

3. Egart M, llic I, Jankovic B, Lah N, Srcic S (2014) Compaction properties of crystalline pharmaceutical ingredients according to the Walker model and nanomechanical attributes. International Journal of Pharmaceutics 472: 347-355.

4. Egart M, llic I, Jankovic B, Lah N, Srcic S (2015) Nanomechanical Properties of Selected Single Pharmaceutical Crystals as a Predictor of Their Bulk Behaviour. Pharmaceutical Research 32: 469-481.
5. Heckel RW (1961) Density-Pressure Relationship in Powder Compaction Trans Met Soc AIME 22: 671-675.

6. Alderborn $\mathrm{G}$ (2007) Tablets and compaction Churchill Livingstone.

7. Jivraj M, Martini LG, Thomson CM (2000) An overview of the different excipients useful for the direct compression of tablets. Pharmaceutical Science \& Technology Today 3: 58-63.

8. Rowe RC, Roberts RJ (1996) Mechanical Properties: Pharmaceutical Powder Compaction Technology, Marcel Dekker, Inc.

9. Sun C, Grant DJ (2001) Influence of elastic deformation of particles on Hecke analysis. Pharm Dev Technol 6: 193-200.

10. Ilić I, Govedarica B, Šibanc R, Dreu R, Srčič S (2013) Deformation properties of pharmaceutical excipients determined using an in-die and out-die method. Int J Pharm 446: 6-15

11. Roberts RJ, Rowe RC (1985) The effect of punch velocity on the compaction of a variety of materials. J Pharm Pharmacol 37: 377-384

12. Gabaude CMD, Guillot M, Gautier JC, Saudemon P, Chulia D (1999) Effects of true density, compacted mass, compression speed, and punch deformation on the mean yield pressure. Journal of Pharmaceutical Sciences 88: 725-730.

13. Denny PJ (2002) Compaction equations: a comparison of the Heckel and Kawakita equations. Powder Technology 127: 162-172.

14. Roberts RJ, Rowe RC (1987) The Compaction of Pharmaceutical and other Model Materials - A Pragmatic Approach. Chemical Engineering Science 903 903-911.

15. Katz JM, Buckner IS (2013) Characterization of strain rate sensitivity in pharmaceutical materials using indentation creep analysis. Int J Pharm 442: 13-19.

16. Fell JT, Newton JM (1971) Effect of particle size and speed of compaction on density changes in tablets of crystalline and spray-dried lactose. J Pharm Sci 60: 1866-1869.

17. McKenna A, McCafferty DF (1982) Effect on particle size on the compaction mechanism and tensile strength of tablets. J Pharm Pharmacol 34: 347-351.

18. Patel S, Kaushal AM, Bansal AK (2007) Effect of particle size and compression force on compaction behavior and derived mathematical parameters of compressibility. Pharm Res 24: 111-124.

19. Sonnergaard JM (1999) A critical evaluation of the Heckel equation. Int $J$ Pharm 193: 63-71.

20. Marshall PV, York P (1993) An investigation of the effect of punch velocity on the compaction properties of ibuprofen Powder Tech. 74: 171-177.

21. Martino D, Beccerica PM, Joiris E, Palmieri GF, Gayot A, et al. (2002) Influence of crystal habit on the compression and densification mechanism of ibuprofen. Journal of Crystal Growth 243: 345-355

22. Patel S, Kaushal AM, Bansal AK (2010) Mechanistic investigation on pressure dependency of Heckel parameter. Int J Pharm 389: 66-73.

23. Liu LX, Marziano I, Bentham AC, Litster JD, White ET, et al. (2013) Influence of particle size on the direct compression of ibuprofen and its binary mixtures. Powder Tech 240: 66-73. 